\title{
Potent anti-tumor and prolonged survival effects of $E$. coli-derived non-glycosylated kringle domain of tissue-type plasminogen activator
}

\author{
BYOUNG-HAK KANG ${ }^{1}$, BYOUNG-SHIK SHIM ${ }^{1}$, SOO YOUNG LEE ${ }^{2}$, \\ SUK-KEUN LEE ${ }^{3}$, YONG-KIL HONG ${ }^{1}$ and YOUNG AE JOE ${ }^{1}$ \\ ${ }^{1}$ Cancer Research Institute, Catholic Research Institutes of Medical Sciences, ${ }^{2}$ Department of Natural Sciences, \\ College of Medicine, The Catholic University of Korea, Seoul 137-701; ${ }^{3}$ Department of Oral Pathology, \\ College of Dentistry, Kangnung National University, Kangnung, Kangwon-Do 210-702, Korea
}

Received September 26, 2005; Accepted November 14, 2005

\begin{abstract}
The two-kringle domain of tissue-type plasminogen activator (TK1-2) has been identified as a novel angiogenesis inhibitor. In the previous study, purified Pichia-derived TK1-2 has been shown to suppress in vivo growth of human lung and colon cancer cells. Here, we demonstrate that E. coliderived non-glycosylated TK1-2 suppresses tumor growth more potently than Pichia-derived TK1-2 and prolongs the survival of tumor bearing mice. The recombinant TK1-2 prepared through E. coli expression, His-tag affinity chromatography and in vitro refolding was injected intraperitoneally once daily into nude mice 7 days after subcutaneous implantation with PC14 lung cancer cells $(n=10)$. Measurement of tumor volumes indicated that low-dose TK1-2 treatment $(10 \mathrm{mg} / \mathrm{kg})$ suppressed tumor growth by approximately $85.2 \%(\mathrm{p}<0.01)$, while high-dose TK1-2 treatment $(50 \mathrm{mg} / \mathrm{kg})$ even more potently inhibited tumor growth $(>93.8 \%)(\mathrm{p}<0.005)$. Treatment of TK1-2 also prolonged the survival of tumor-bearing mice in a dose-dependent fashion. In an independent HCT116 xenograft model, E. coli-derived TK1-2 was more effective in suppressing tumor growth than Pichia-derived TK1-2. Immunohistochemical analysis of tumor tissue also revealed that the expression of VEGF, SMA- $\alpha$, TNF- $\alpha$ and angiogenin was less positive in the E. coli-derived TK1-2-treated group than in the Pichia-derived TK1-2-treated group. These results suggest that $E$. coli-derived refolded, non-glycosylated TK1-2 can be used more effectively as an anti-cancer agent.
\end{abstract}

Correspondence to: Dr Young Ae Joe, Cancer Research Institute, Catholic Research Institutes of Medical Science, The Catholic University of Korea, Banpo-dong 505, Seocho-ku, Seoul 137-701, Korea

E-mail: youngjoe@catholic.ac.kr

Key words: PC14 lung cancer, angiogenesis, survival, tissue-type plasminogen activator, kringle, inhibitor

\section{Introduction}

Angiogenesis, the process of new capillary outgrowth from pre-existing vessels, is essential for embryonic development, organ formation, wound healing, female reproduction, and tissue regeneration and remodeling $(1,2)$. Many studies also indicate that tumor growth and metastasis depend on angiogenesis (3-8). Down-regulation of angiogenesis activators and up-regulation of angiogenesis inhibitors for modulating the angiogenic switch have therefore been an important strategy for preventing angiogenesis in cancer. Moreover, additional benefits, including that angiogenesis inhibitors are relatively less toxic than conventional chemotherapy and have a lower risk of drug resistance, have also encouraged the use of angiogenesis inhibitors as a promising therapeutic strategy for intervening cancer prevention or progression.

Since angiostatin, one of the potent endogenous angiogenesis inhibitors, was isolated from the serum and urine of tumor-bearing animals (3), several other proteins (called kringle domain) with the same architecture have been identified as anti-angiogenic molecules. PK5 of plasminogen, kringle 2 of prothrombin, kringle 1 of human hepatocyte growth factor, and the kringle of urokinase-type plasminogen activator have been shown to inhibit endothelial cell proliferation (9-12). Two recombinant kringles, NK4 derived from hepatocyte growth factor and rhLK68 derived from apolipoprotein(a), have also displayed in vivo anti-tumor activity in xenograft animal models $(13,14)$. Two kringle domain of tissue-type plasminogen activator (t-PA), named as TK1-2, also inhibits in vitro endothelial proliferation and in vivo embryo angiogenesis, despite low amino-acid sequence identity (26-39\%) between t-PA and angiostatin kringles (15).

Recently, we have shown the in vivo anti-tumor activity of TK1-2 using a purified recombinant protein produced in Pichia pastoris (16). In the previous study, we also found that $E$. coli-derived refolded TK1-2 possesses in vitro potent anti-proliferative activity on endothelial cells, comparable to Pichia-derived TK1-2 (15). E. coli-derived TK1-2 (E-TK1-2) is different from Pichia-derived TK1-2 (P-TK1-2) in terms of glycosylation modifications, since this domain has two 
$\mathrm{N}$-linked glycosylation sites (17). In the case of t-PA, the parent molecule of TK1-2, glycosylation at Asn117 (kringle 1) and Asn184 (kringle 2) affects fibrin affinity and plasma clearance (18-20). Therefore, we investigated how nonglycosylated E-TK1-2 affects tumor growth in vivo. Here, we report that systemic administration of E-TK1-2 potently and dose-dependently suppressed in vivo growth of PC14 cancer cells in nude mice and prolonged the survival of tumor-bearing mice. We also show that the anti-tumor effect of E-TK1-2 is more potent than that of P-TK1-2 in HCT116 xenografted mice.

\section{Materials and methods}

Reagents and cells. Isopropyl thio- $\beta-\mathrm{D}$-galactopyranoside (IPTG) was purchased from Amnesco (Solon, OH), DNase I, from Boehringer-Mannheim (Mannheim, Germany), RNase A from Sigma (St. Louis, MO), and Probond resin from Invitrogen (Carlsbad, CA). Dulbecco's modified Eagle's medium (DMEM) and RPMI-1640 medium were purchased from Jeil Biotechservices Inc. (Daegu, Korea). Fetal bovine serum (FBS) and trypsin solution were purchased from Life Technologies, Inc. (Gaithersburg, MD). The human lung cancer cell line, PC14, was obtained from the National Cancer Institute (Tokyo, Japan). The human lung cancer cell line, HCT116, was obtained from the American Type Culture Collection. PC14 cells were cultured in DMEM supplemented with $10 \%$ FBS and HCT116 cells were cultured in RPMI-1640 supplemented with $10 \%$ FBS.

Production of recombinant TK1-2. E-TK1-2 was produced as described previously (15). Briefly, the E. coli transformant was grown and then induced for $3 \mathrm{~h}$ by adding isopropyl thio-ß-D-galactopyranoside (IPTG). The cells were harvested by centrifugation for $15 \mathrm{~min}(8,000 \mathrm{x} \mathrm{g})$, and refolding and purification of TK1-2 were carried out as follows. The cell pellet was suspended in a lysis buffer $(20 \mathrm{mM}$ Tris-Cl, $\mathrm{pH} 8.0$, $50 \mathrm{mM} \mathrm{NaCl}, 1 \mathrm{mM} \mathrm{MgCl}, 0.1 \mathrm{mM} \mathrm{CaCl}_{2}, \mathrm{RNase}_{2}$ A $20 \mu \mathrm{g}$ / $\mathrm{ml}$, DNase I $50 \mu \mathrm{g} / \mathrm{ml}$ ), and subjected to sonication for $15 \mathrm{~min}$. Soluble and insoluble fractions were separated by centrifugation for $30 \mathrm{~min}$ at $20,000 \mathrm{x} \mathrm{g}$. The insoluble fraction was dissolved in buffer A (20 mM Tris-Cl, pH 7.9, 0.5 M NaCl, $6 \mathrm{M}$ Urea). After centrifugation for $30 \mathrm{~min}$ at $18,000 \mathrm{rpm}$, the supernatant was applied to a ProBond ${ }^{\mathrm{TM}}$ resin His-tag affinity column (Invitrogen). The column was washed with buffer A containing $20 \mathrm{mM}$ imidazole, and protein was eluted using buffer A containing $1 \mathrm{M}$ imidazole. The eluate was stepwise diluted with $0.1 \mathrm{M}$ Tris- $\mathrm{Cl}, 0.15 \mathrm{M} \mathrm{NaCl}, \mathrm{pH} 8.0$, followed by addition of reduced $(1 \mathrm{mM})$ and oxidized $(0.1 \mathrm{mM})$ glutathione, and incubated at room temperature overnight. The solution was concentrated by ultrafiltration and dialyzed against sodium acetate buffer $(\mathrm{pH}$ 5.5) and distilled water. The endotoxin content of purified TK1-2 used for cell assays did not exceed 0.4 endotoxin units/mg protein. P-TK1-2 was prepared by expression in Pichia pastoris as reported previously (16).

MALDI analysis. Matrix-assisted laser desorption ionization (MALDI) mass spectrometry was performed using a VoyagerDE $^{\text {TM }}$ STR Biospectrometry work station with a linear mass analyzer (Applied Biosystems, Foster City, CA) (21). The machine was located at the Korea Basic Science Institute (Seoul, Korea).

Animal studies. Six-week-old male nude mice (BALB/c nu/nu; Japan SLC, Inc., Hamamatsu, Japan) were subcutaneously injected through the right flank with $200 \mu 1$ of PC14 cells $\left(3 \times 10^{6}\right.$ cells). The mice were randomly divided into three groups, 7 days after implantation. The mice of the treatment group were injected i.p. every day for 50 days with E-TK1-2 protein $(10 \mathrm{mg} / \mathrm{kg}$, or $50 \mathrm{mg} / \mathrm{kg})$, while control group mice were injected with PBS. The size of the tumors in all groups was measured every 2-3 days using a caliper, and the volume of the tumors was determined using the formula, width ${ }^{2} \mathrm{x}$ length $x 0.52$ (22).

In a second set of experiments, six-week-old nude mice were implanted by injection of $100 \mu 1$ PBS containing all $3 \times 10^{6}$ cells of the HCT116 cancer cell line in the right flank. After 24 days, the mice were randomly divided into three groups. The mice were injected i.p. every day for 28 days with PBS, E-TK1-2 or P-TK1-2 at a single dose of $30 \mathrm{mg} / \mathrm{kg}$. Measurement of tumor volume was carried out using the same formula as above.

Histological and immunohistochemical analysis. Tumors were dissected from sacrificed animals, fixed in $10 \%$ buffered formalin solution and then embedded in paraffin according to standard histological procedures. The embedded tissue was sectioned (4 $\mu \mathrm{m}$ thickness), deparaffinized with xylene and then stained with hematoxylin and eosin, and also by using immunohistochemical methods with monoclonal antibodies against proliferating cell nuclear antigen (PCNA; Dako, Denmark), von Willebrand factor (vWF; R\&D Systems, Inc., Minneapolis, MN), $\alpha$-smooth muscle actin ( $\alpha$-SMA; Sigma), angiogenin (R\&D Systems, Inc.,), vascular endothelial growth factor (VEGF; R\&D systems, Inc.), hypoxia inducible factor $1 \alpha$ (HIF-1 $\alpha$; Novus Biological, Littleton, CO), and tumor necrosis factor $\alpha$ (TNF- $\alpha$; Santa Cruz Biotechnology Inc., Santa Cruz, CA). Sections were sequentially incubated with biotin-labeled secondary antibodies and streptavidin-peroxidase complex (Dako), and visualized using diaminobenzidine (DAB) colorization (DiNonA, Seoul, Korea).

To detect apoptotic cells in tissue sections, the terminal deoxynucleotidyl transferase-mediated dUTP-biotin nick endlabeling (TUNEL) method was applied using the ApopTag In Situ apoptosis detection kit (Oncor, Gaithersburg, MD) according to the manufacturer's instructions.

\section{Results}

Potent suppression of PC14 tumor growth by E. coli-derived TK1-2. We previously demonstrated that E-TK1-2 inhibits endothelial cell proliferation in vitro and vessel formation on chick chorioallantoine membrane (15). In this study, we investigated whether E-TK1-2 inhibits in vivo tumor growth in xenograft animal models. We used the same recombinant $E$. coli strain as used before, and adopted an identical purification and refolding process for producing recombinant TK1-2. Briefly, recombinant E-TK1-2 was obtained by solubilization of inclusion bodies, $\mathrm{Ni}^{+}$-chelate chromatography, and in vitro refolding. Purified refolded E-TK1-2 migrated 


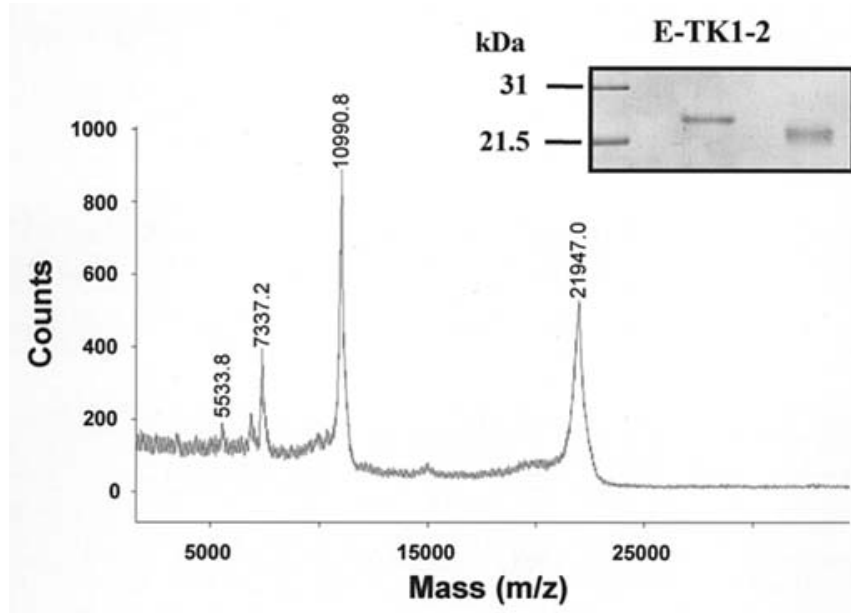

Figure 1. Characterization of E-TK1-2. Mass spectrum was measured for purified E-TK1-2. The single major peak represents a molecular mass of 21,947.0 $\mathrm{Da}$. The sample was analyzed under reducing (left lane) and nonreducing (right lane) conditions.

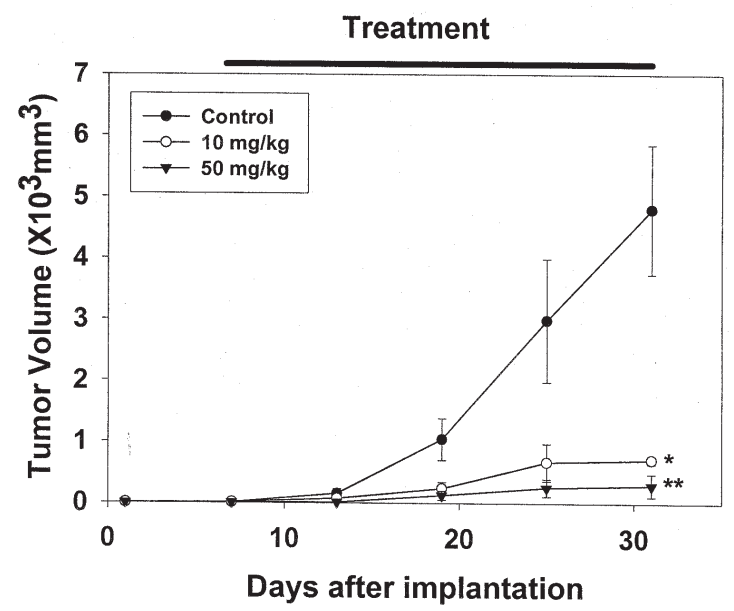

Figure 2. Potent inhibition of in vivo PC14 cancer cell growth by E-TK1-2 in a dose-dependent fashion. Male BALB/c-nu mice were subcutaneously implanted with $3 \times 10^{6} \mathrm{PC} 14$ tumor cells per mouse and then i.p. administered daily PBS (closed circle) or recombinant E-TK1-2 at $10 \mathrm{mg} / \mathrm{kg}$ (open circle) or $50 \mathrm{mg} / \mathrm{kg}$ (reverse triangle) 7 days after implantation. Data represent the mean tumor volumes in the ten mice of each group $( \pm \mathrm{SE}) .{ }^{*} \mathrm{P}<0.01$; ${ }^{* *} \mathrm{P}<0.005$.

on SDS-PAGE as a single band of approximately $22 \mathrm{kDa}$ under a non-reducing condition, and MALDI analysis demonstrated one peak at 21947.0 Da (Fig. 1).

We examined whether E-TK1-2 could suppress tumor growth in vivo. PC14 human lung cancer cells were s.c. implanted into nude mice and, once the tumor was visible at day 7 after implantation, mice were i.p. administered either PBS (control) or E-TK1-2 (10 or $50 \mathrm{mg} / \mathrm{kg}$ ) daily ( $\mathrm{n}=10)$. At day 31 after implantation (treatment for 23 days), tumor volumes were compared between control and treated groups. We found that low-dose TK1-2 treatment (10 mg/kg) suppressed tumor growth by approximately $85.2 \%(\mathrm{p}<0.01)$ and high-dose TK1-2 treatment $(50 \mathrm{mg} / \mathrm{kg})$ even more potently inhibited tumor growth $(>93.8 \%)(\mathrm{p}<0.005)($ Fig. 2). E-TK1-2 also significantly prolonged the survival of tumor-bearing

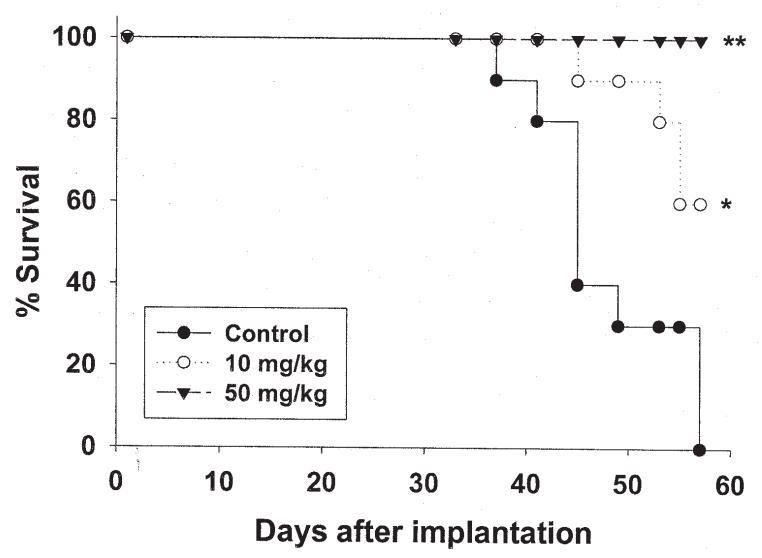

Figure 3. Prolonged survival of mice treated with 10 or $50 \mathrm{mg} / \mathrm{kg}$ E-TK1-2 compared to PBS-treated mice (control) ( $\mathrm{n}=10 /$ group). Differences in animal survival among groups were evaluated using the log-rank test. ${ }^{*} \mathrm{P}<0.005$; ${ }^{* *} \mathrm{P}<0.0001$.

mice in a dose-dependent fashion (Fig. 3). At day 58 after implantation, the survival rates of mice treated with E-TK1-2 at 10 and $50 \mathrm{mg} / \mathrm{kg} /$ day were 60 and $100 \%$, respectively, in contrast to $0 \%$ in the control group. Toxic signs, including weight loss and metastasis, were not observed in any E-TK1-2treated mice.

Comparison of anti-tumor effects of two TK1-2 recombinant proteins in HCT116 xenografted mice. The anti-tumor effects of purified TK1-2 expressed in Pichia or E. coli were determined at the same time in HCT116 cancer-bearing mice. Following implantation of HCT116 cancer cells, recombinant P-TK1-2 or E-TK1-2 was administered at a single daily dose of $30 \mathrm{mg} / \mathrm{kg}$. Tumor sizes at the time of initial treatment were approximately $382-624 \mathrm{~mm}^{3}$. Measurement of tumor volumes indicated that both P-TK1-2 and E-TK1-2 suppressed tumor growth (Fig. 4A), with slower growth rates observed in the treated groups compared with the PBS-treated control group. The difference in tumor volume between control and treated groups was apparent at day 10 after the initiation of treatment. At day 19, tumor volumes in the groups treated with E-TK1-2 and PTK1-2 were suppressed by $74.3 \%(\mathrm{p}<0.005)$, and $54 \%(\mathrm{p}<0.05)$ compared to those of the control group treated with PBS. The difference in inhibition of tumor growth by these two proteins became larger after treatment for 19 days. After 27 days of treatment, E-TK1-2 suppressed tumor growth by $81.3 \%$ $(\mathrm{p}<0.005)$, and P-TK1-2, by $47.8 \%(\mathrm{p}<0.05)$. When we checked the weight of the tumors removed from the mice after sacrifice at day 28 , the inhibition level of tumor growth by tumor weight was similar to that measured by tumor volume (Fig. 4B). One of the mice treated with E-TK1-2 no longer had a tumor. Upon treatment of E-TK1-2 and P-TK1-2, the weight of tumors was decreased by $72.5 \%(\mathrm{p}<0.001)$ and $36.5 \%(\mathrm{p}<0.001)$, respectively, compared to that of untreated tumors. No signs of toxicity or metastasis were observed in any of the treated mice.

Effect of TK1-2 on expression of angiogenesis-related factors and apoptosis. The effect of TK1-2 administration on tumor tissue was evaluated using immunohistochemical staining. 


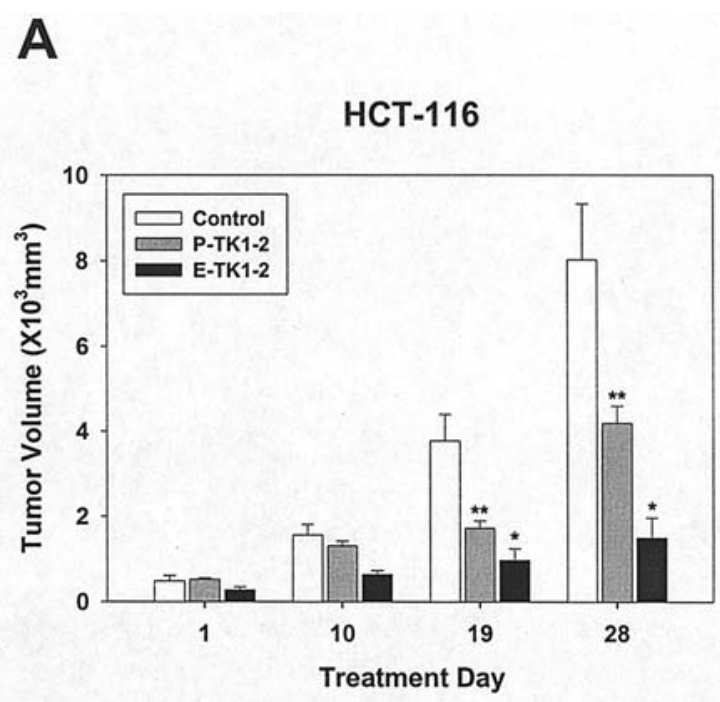

B
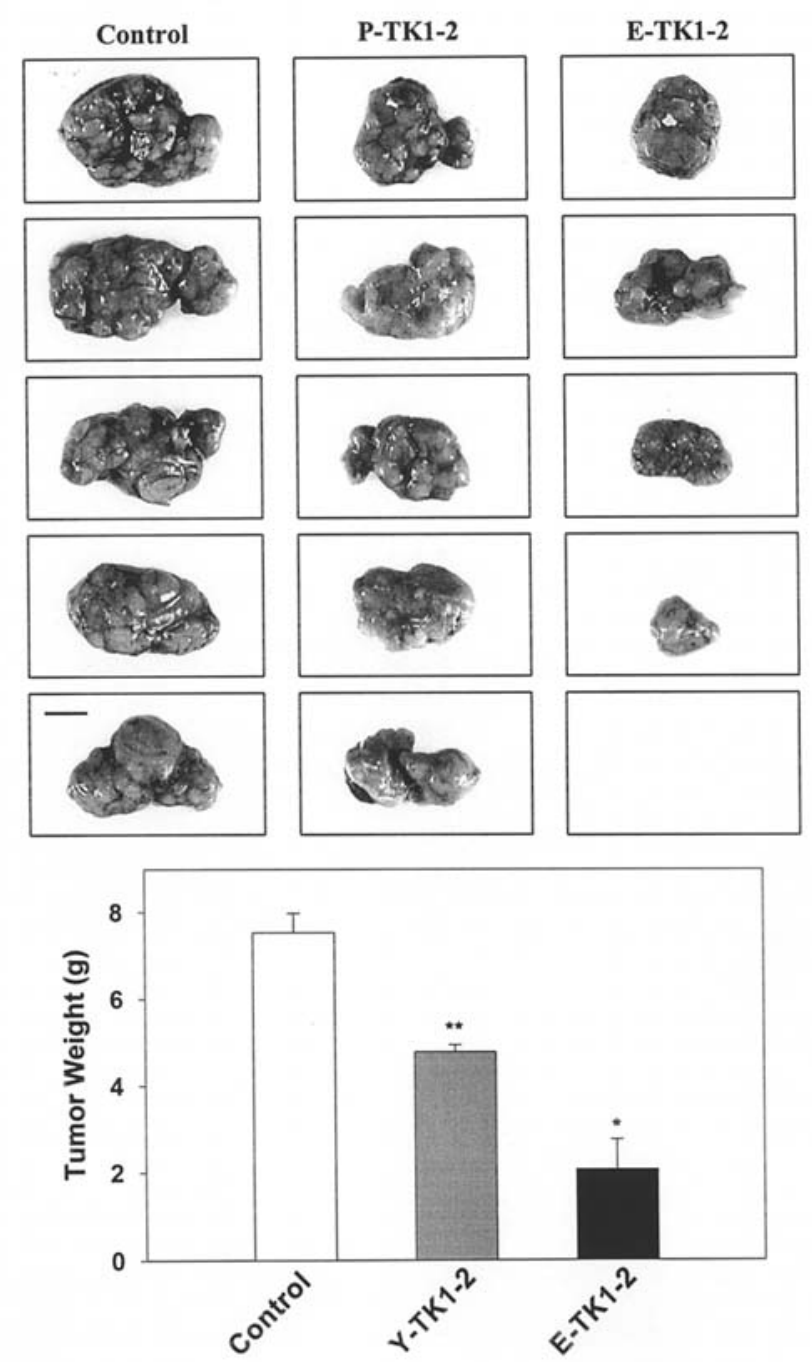

Figure 4. Inhibition of tumor growth by E-TK1-2 and P-TK1-2 in HCT116 xenografted mice. Male BALB/c-nu mice were subcutaneously implanted with $3 \times 10^{6}$ HCT 116 colon cancer cells per mouse and then i.p. administered PBS (control) or $30 \mathrm{mg} / \mathrm{kg}$ recombinant TK1-2 daily for 28 days. (A) Tumor volume was determined in the five mice of each group and expressed as a percentage of control ( $\pm \mathrm{SE}$ ). ${ }^{*} \mathrm{P}<0.005 ;{ }^{* *} \mathrm{P}<0.05$. (B) The tumors were removed from sacrificed mice and their weight was measured. Bar indicates $1.0 \mathrm{~cm} .{ }^{*} \mathrm{P}<0.001$
The cutting surface of both control and TK1-2-treated tumor tissues revealed active proliferation of tumor cells with a lot of vascular channels in the peripheral zone and severe necrosis in the central zone. The tumor tissues treated with TK1-2 usually showed polygonal tumor cells arranged loosely, while those of the control group showed spindle tumor cells arranged relatively tightly (Fig. 5, 1a-c).

Upon treatment with TK1-2, the changes in the expression of angiogenesis-related factor, TUNEL staining, and PCNA immunoreactivity were measured among the control group, P-TK1-2-treated group, and E-TK1-2-treated group (Figs. 5 and 6). In parenchymal tumor tissue, the number of TUNELpositive tumor cells was most increased in the E-TK1-2treated-group, followed by the P-TK1-2-treated group and control group. The immunoreaction of HIF-1 $\alpha$ was also most increased in the E-TK1-2-treated group (Fig. 5, 6a-c). These findings are consistent with the results of previous studies showing that the inhibition of tumor neovasculature by an angiogenesis inhibitor leads to increased apoptosis in tumor tissue $(23,24)$. Immunostaining for angiogenesis-related factors angiogenin, vWF, $\alpha$-SMA, VEGF and TNF- $\alpha$ indicated that their expression was dramatically decreased in tumor cells treated with TK1-2 compared to those of control mice (Fig. 5, 2-7). These immunoreactions were conspicuously weaker in the E-TK1-2-treated group than in the P-TK1-2treated group.

\section{Discussion}

t-PA, one of the fibrinolysis-related proteins, has two kringle domains with approximately $29-39 \%$ identity to angiostatin kringles. In spite of that, in the previous study, yeast-derived TK1-2 suppresses tumor growth in vivo, without inhibition of t-PA activity and any signs of toxicity, although it does not affect in vitro growth of cancer cells (16). Here, we used a different recombinant protein obtained through $E$. coli expression and in vitro refolding. E-TK1-2 is different from P-TK1-2 in terms of lack of glycosylation. Interestingly, we found that E-TK1-2 is more effective in tumor suppression in vivo, although E-TK1-2 possesses similar in vitro antiproliferative activity on endothelial cells to P-TK1-2 (15) and no inhibitory activity on PC14 or HCT116 cancer cell growth in vitro (data not shown).

We also displayed a dose-dependency in anti-tumor effect of TK1-2, which has not been shown in the previous study. E-TK1-2 showed marked inhibition, even at a dose of $10 \mathrm{mg} /$ $\mathrm{kg} /$ day $(85.2 \%)$. When treated at a dose of $50 \mathrm{mg} / \mathrm{kg} / \mathrm{day}$, the inhibition was remarkably almost complete (93.8\%). Moreover, the survival rate also showed a dose dependency, suggesting that inhibition of tumor angiogenesis prevents tumor growth and thereby improves survival rate. Considering previous results that treatment of P-TK1-2 at a single dose, $30 \mathrm{mg} / \mathrm{kg}$ / day, suppressed tumor growth by $52.4-85.3 \%$ in xenografted models (16), the inhibitory effect of E-TK1-2 on in vivo tumor growth seems more potent.

In a murine xenograft model of human HCT116 lung cancer cells, it became obvious that E-TK1-2 is more potent in suppression of tumor growth. At day 28 after the initiation of treatment, E-TK1-2 suppressed tumor growth by $81.3 \%$ whereas P-TK1-2 suppressed it by $47.8 \%$. At this point, we can 

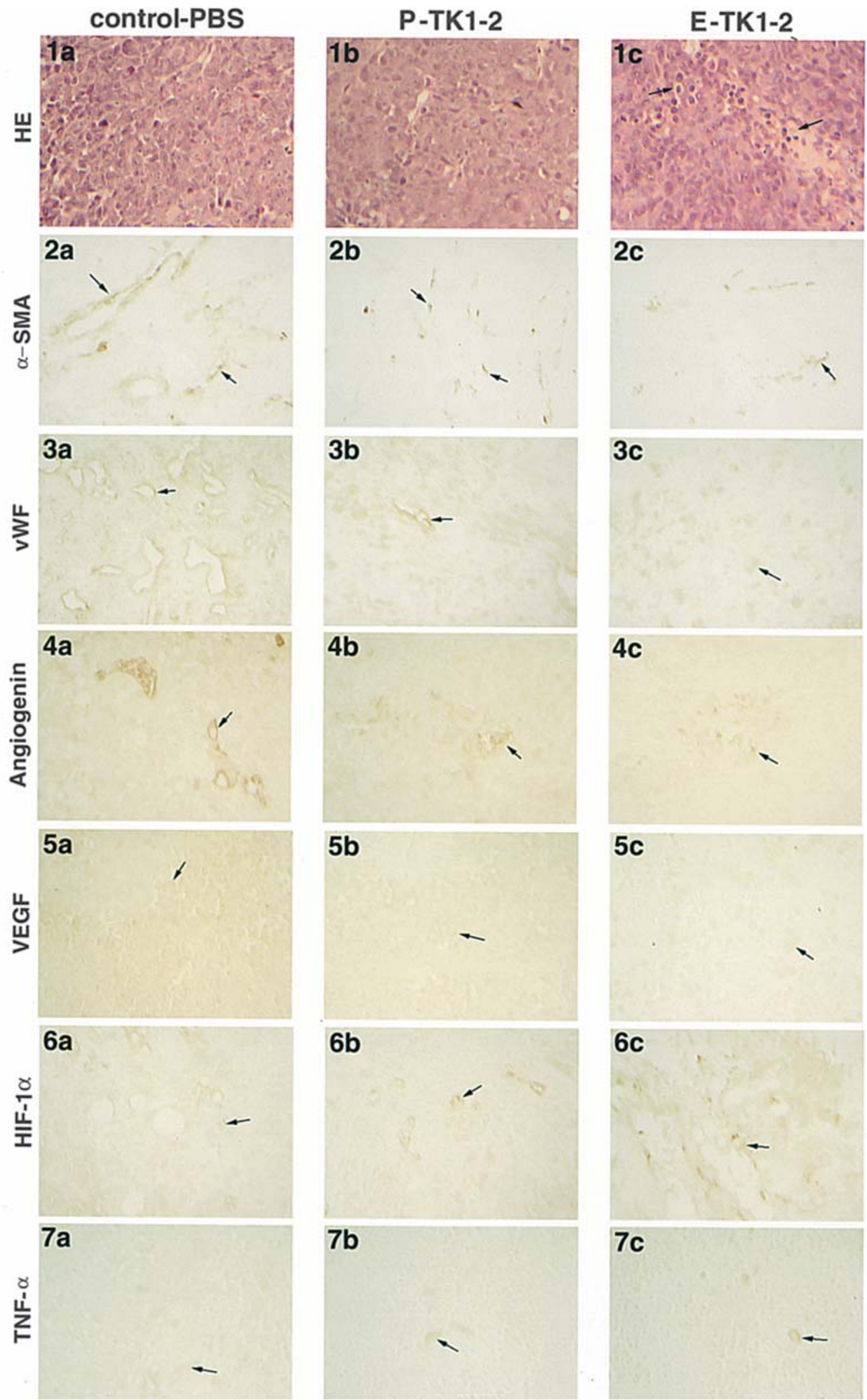

Figure 5. Photomicrographs of representative sections of tumor tissues obtained from control and TK1-2-treated mice implanted with HCT116 cancer cells. a, control group treated with PBS solution; b, P-TK1-2-treated group; c, E-TK1-2-treated group. 1, H\&E staining. 2-7, immunohistochemical staining. 2, $\alpha$-SMA; 3 , vWF; 4, angiogenin; 5, VEGF; 6 , HIF-1 $\alpha ; 7$, TNF- $\alpha$. Representative positive reactions were indicated by arrows. Magnification, $\mathrm{x} 400$.

not explain clearly why such a difference in in vivo anti-tumor effects arose. In the case of angiostatin, its mutant recombinant protein produced in Pichia after removal of the glycosylated site through site-directed mutagenesis retained in vivo antitumor effects (25), and the non-glycosylated form produced in $E$. coli also showed potent anti-tumor effects in a brain tumor animal model (26). However, there has been no direct comparison of anti-tumor effects between the glycosylated and non-glycosylated forms of one identical protein so far. From such differences in anti-tumor activity between the two 

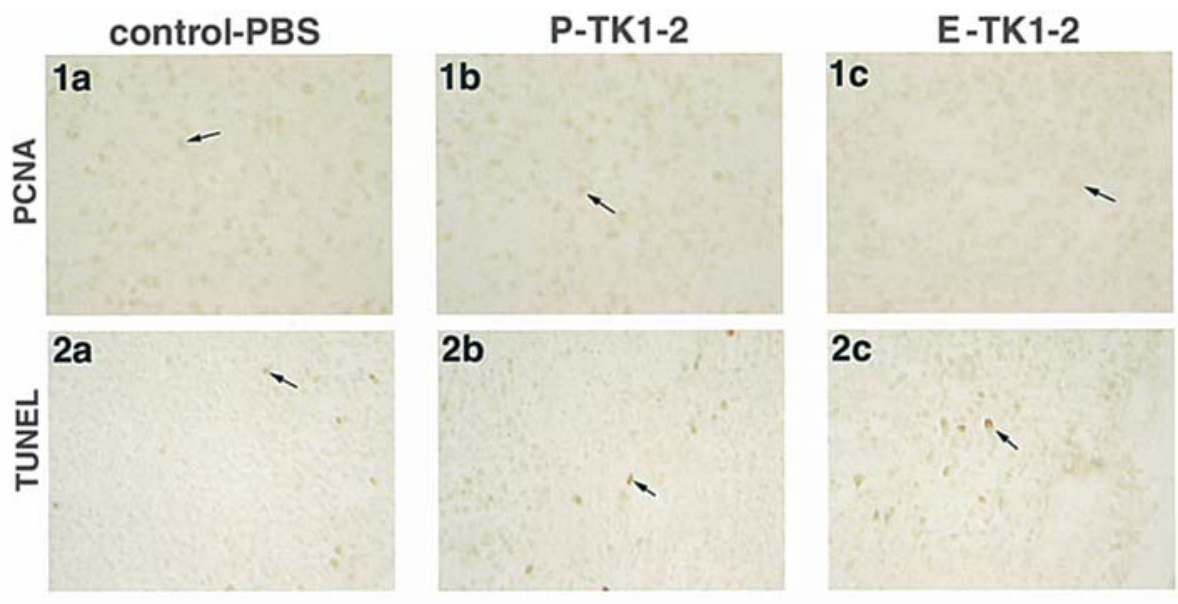

3.

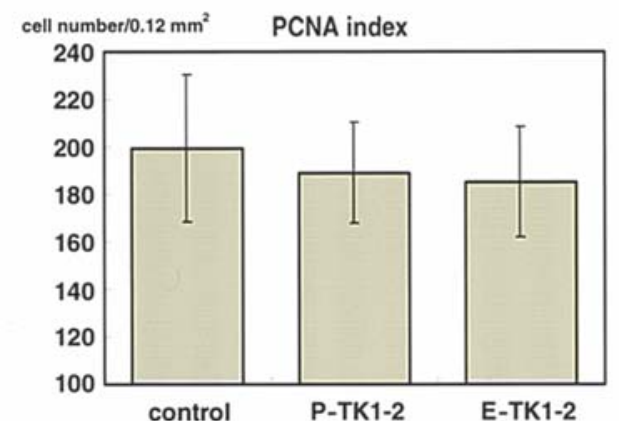

4.

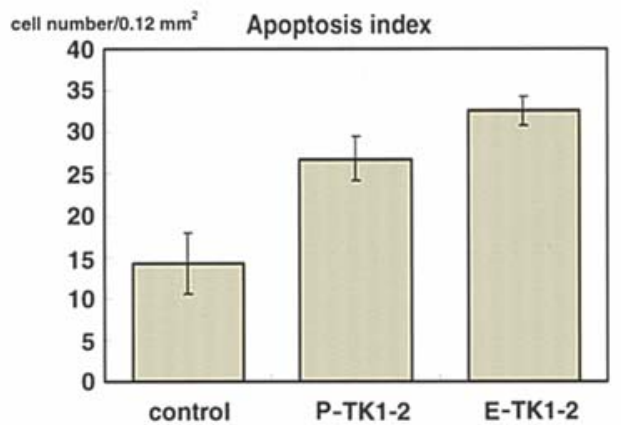

Figure 6. Immunohistochemical reaction of PCNA and TUNEL staining in tumor tissue obtained from control and TK1-2 treated mice implanted with HCT116 cancer cells. a, control group treated with PBS; b, P-TK1-2-treated group; c, E-TK1-2-treated group. 1, PCNA expression; 2, TUNEL staining; 3, PCNA index among the three different groups, which was measured by the number of PCNA-positive cells per $0.12 \mathrm{~mm}^{2}$ of tissue; 4 , apoptosis index among the three different groups, which was measured using TdT labeling to identify the number of cells with fragmented DNA per 0.12 mm ${ }^{2}$ of tissue. Representative data are shown.

TK1-2 recombinant proteins in this study, we consider the possibility that non-glycosylated TK1-2 can be more delayed from clearance, since we could not detect a difference in effects on in vitro endothelial cell and cancer cell growth, and the sugar moiety at Asn117 carrying a high mannose structure may be involved in the rapid clearance of t-PA from plasma by the liver (18).

E-TK1-2 treatment also affected angiogenesis-related protein expression and apoptotic index in tumor tissues. The change level was higher than that which resulted from P-TK1-2 treatment. Immunohistochemical analysis showed that TK1-2 inhibited the expression of the pro-angiogenic factors, VEGF, angiogenin and TNF- $\alpha$. Decreased expression of vWF and $\alpha$-SMA is consistent with reduced expression of the important angiogenic factors, angiogenin and VEGF. TNF- $\alpha$ is known to be pro-angiogenic in vivo, despite its reported anti-angiogenic properties in vitro $(27,28)$. Down-regulation of VEGF has also been observed following administration of several angiogenesis inhibitors, including recombinant PK1-3 (26), plasminogen kringle 5 (PK5) (29) and apolipoprotein kringles (14), and also following adenoviral vector delivery of angiostatin and endostatin (30). It remains to be elucidated as to how TK1-2 reduces the expression of angiogenic factors in in vivo models.

The molecular mechanisms underlying the effect of angiostatin on angiogenesis are not yet clear. Similarly, the molecular and cellular mechanisms underlying the actions of TK1-2 also remain to be elucidated. In the previous study, we showed that both recombinant TK1-2 proteins selectively inhibit endothelial cell proliferation (15). In relation to t-PA activity, E-TK1-2 and P-TK1-2 similarly had no effect on fibrinolysis (data not shown). Since non-glycosylated TK1-2 is as effective as glycosylated TK1-2 in the inhibition of endothelial cell proliferation, the sugar moiety of TK1-2 may not be involved in its anti-angiogenic activity; rather, it could be involved in plasma clearance. In conclusion, we suggest that $E$. coliderived, non-glycosylated TK1-2 recombinant protein could be a better candidate in developing an anti-cancer drug.

\section{Acknowledgements}

This study was supported by a grant from the Korea Health 21 R\&D Project (HMP-01-PJ1-PG3-20800-0116), Ministry of Health \& Welfare, Republic of Korea.

\section{References}

1. Folkman J and D'Amore PA: Blood vessel formation: what is its molecular basis? Cell 87: 1153-1155, 1996.

2. Risau W: Mechanisms of angiogenesis. Nature 386: 671-674, 1997.

3. O'Reilly MS, Holmgren L, Shing Y, Chen C, Rosenthal RA, Moses M, Lane WS, Cao Y, Sage EH and Folkman J: Angiostatin: a novel angiogenesis inhibitor that mediates the suppression of metastases by a Lewis lung carcinoma. Cell 79: 315-328, 1994. 
4. Folkman J: Angiogenesis in cancer, vascular, rheumatoid and other disease. Nat Med: 27-31, 1995.

5. Kim KJ, Li B, Winer J, Armanini M, Gillett N, Phillips HS and Ferrara N: Inhibition of vascular endothelial growth factorinduced angiogenesis suppresses tumour growth in vivo. Nature 362: 841-844, 1993.

6. Brooks PC, Montgomery AM, Rosenfeld M, Reisfeld RA, Hu T, Klier $\mathrm{G}$ and Cheresh DA: Integrin alpha $\mathrm{v}$ beta 3 antagonists promote tumor regression by inducing apoptosis of angiogenic blood vessels. Cell 79: 1157-1164, 1994.

7. Good DJ, Polverini PJ, Rastinejad F, Le Beau MM, Lemons RS, Frazier WA and Bouck NP: A tumor suppressor-dependent inhibitor of angiogenesis is immunologically and functionally indistinguishable from a fragment of thrombospondin. Proc Natl Acad Sci USA 87: 6624-6628, 1990.

8. Choi SH, Lee JH, Hong SH, Hyung WJ, Noh SH, Chung HC, Roh JK and Min JS: Suppression of peritoneal metastases by expression of murine endostatin cDNA. Cancer Res Treat 34: 302-307, 2002.

9. Cao Y, Chen A, An SS, Ji RW, Davidson D and Llinas M: Kringle 5 of plasminogen is a novel inhibitor of endothelial cell growth. J Biol Chem 272: 22924-22928, 1997.

10. Lee TH, Rhim T and Kim SS: Prothrombin kringle-2 domain has a growth inhibitory activity against basic fibroblast growth factor-stimulated capillary endothelial cells. J Biol Chem 273: 28805-28812, 1998.

11. Xin L, Xu R, Zhang Q, Li TP and Gan RB: Kringle 1 of human hepatocyte growth factor inhibits bovine aortic endothelial cell proliferation stimulated by basic fibroblast growth factor and causes cell apoptosis. Biochem Biophys Res Commun 277: 186-190, 2000.

12. Kim KS, Hong YK, Joe YA, Lee Y, Shin JY, Park HE, Lee IH, Lee SY, Kang DK, Chang SI and Chung SI: Anti-angiogenic activity of the recombinant kringle domain of urokinase and its specific entry into endothelial cells. J Biol Chem 278: 11449-11456, 2003.

13. Kuba K, Matsumoto K, Date K, Shimura H, Tanaka M and Nakamura T: HGF/NK4, a four-kringle antagonist of hepatocyte growth factor, is an angiogenesis inhibitor that suppresses tumor growth and metastasis in mice. Cancer Res 60: 6737-6743, 2000 .

14. Kim JS, Chang JH, Yu HK, Ahn JH, Yum JS, Lee SK, Jung KH, Park DH, Yoon Y, Byun SM and Chung SI: Inhibition of angiogenesis and angiogenesis-dependent tumor growth by the cryptic kringle fragments of human apolipoprotein(a). J Biol Chem 278: 29000-29008, 2003.

15. Kim HK, Lee SY, Oh HK, Kang BH, Ku HJ, Lee Y, Shin JY, Hong YK and Joe YA: Inhibition of endothelial cell proliferation by the recombinant kringle domain of tissue-type plasminogen activator. Biochem Biophys Res Commun 304: 740-746, 2003.

16. Shim BS, Kang BH, Hong YK, Kim HK, Lee IH, Lee SY, Lee YJ, Lee SK and Joe YA: The kringle domain of tissue-type plasminogen activator inhibits in vivo tumor growth. Biochem Biophys Res Commun 327: 1155-1162, 2005.
17. Pohl G, Kallstrom M, Bergsdorf N, Wallen P and Jornvall H: Tissue plasminogen activator: peptide analyses confirm an indirectly derived amino acid sequence, identify the active site serine residue, establish glycosylation sites, and localize variant differences. Biochemistry 23: 3701-3707, 1984.

18. Smedsrod B and Einarsson M: Clearance of tissue plasminogen activator by mannose and galactose receptors in the liver. Thromb Haemost 63: 60-66, 1990.

19. Otter M, Barrett-Bergshoeff MM and Rijken DC: Binding of tissue-type plasminogen activator by the mannose receptor. J Biol Chem 266: 13931-13935, 1991.

20. Aoki S, Shimizu N, Shimonishi M, Kitagawa M, Okumura K and Tanigawara $Y$ : Influence of sugar chain on fibrin affinity of recombinant t-PA. Biol Pharm Bull 24: 295-298, 2001.

21. Kim HJ and Park S: Investigation of hydroxyl radical-induced cross-linking of peptides and its inhibition by matrix-assisted laser desorption/ionization time-of-flight mass spectrometry. Bull Korean Chem Soc 20: 370-372, 1999.

22. Cao Y, O'Reilly MS, Marshall B, Flynn E, Ji RW and Folkman J: Expression of angiostatin cDNA in a murine fibrosarcoma suppresses primary tumor growth and produces long-term dormancy of metastases. J Clin Invest 101: 1055-1063, 1998.

23. Holmgren L, O'Reilly MS and Folkman J: Dormancy of micrometastases: balanced proliferation and apoptosis in the presence of angiogenesis suppression. Nat Med 1: 149-153, 1995.

24. O'Reilly MS, Holmgren L, Chen C and Folkman J: Angiostatin induces and sustains dormancy of human primary tumors in mice. Nat Med 2: 689-692, 1996.

25. Sim BK, O'Reilly MS, Liang H, Fortier AH, He W, Madsen JW, Lapcevich R and Nacy CA: A recombinant human angiostatin protein inhibits experimental primary and metastatic cancer. Cancer Res 57: 1329-1334, 1997.

26. Joe YA, Hong YK, Chung DS, Yang YJ, Kang JK, Lee YS, Chung SI, You WK, Lee $\mathrm{H}$ and Chung SI: Inhibition of human malignant glioma growth in vivo by human recombinant plasminogen kringles 1-3. Int J Cancer 82: 694-699, 1999.

27. Frater-Schroder M, Risau W, Hallmann R, Gautschi P and Bohlen P: Tumor necrosis factor type alpha, a potent inhibitor of endothelial cell growth in vitro, is angiogenic in vivo. Proc Natl Acad Sci USA 84: 5277-5281, 1987.

28. Ueda T, Ueda T, Fukuda S, Browne R, Jenis E, Spengler R, Chou R, Buch P, Aljada A, Dandona P, Sasisekharan R, Dorey CK and Armstrong D: Lipid hydroperoxide-induced tumor necrosis factor (TNF)-alpha, vascular endothelial growth factor and neovascularization in the rabbit cornea: effect of TNF inhibition. Angiogenesis 1: 174-184, 1998.

29. Gao G, Li Y, Gee S, Dudley A, Fant J, Crosson C and Ma JX: Down-regulation of vascular endothelial growth factor and up-regulation of pigment epithelium-derived factor: a possible mechanism for the anti-angiogenic activity of plasminogen kringle 5. J Biol Chem 277: 9492-9497, 2002.

30. Hajitou A, Grignet C, Devy L, Berndt S, Blacher S, Deroanne CF, Bajou K, Fong T, Chiang Y, Foidart JM and Noel A: The antitumoral effect of endostatin and angiostatin is associated with a down-regulation of vascular endothelial growth factor expression in tumor cells. FASEB J 16: 1802-1804, 2002. 